\title{
Health-Related Direct-to-Consumer Genetic Tests: A Public Health Assessment and Analysis of Practices Related to Internet-Based Tests for Risk of Thrombosis
}

\author{
K.A.B. Goddard ${ }^{a-c}$ J. Robitaille ${ }^{d, e} \quad$ N.F. Dowling ${ }^{b} \quad$ A.R. Parrado ${ }^{a} \quad$ J. Fishman ${ }^{f, g}$ \\ L.A. Bradley ${ }^{\text {b }}$ C.A. Moore ${ }^{d}$ M.J. Khoury ${ }^{b}$ \\ a Department of Epidemiology and Biostatistics, Case Western Reserve University, Cleveland, Ohio, \\ ${ }^{b}$ National Office of Public Health Genomics, Centers for Disease Control and Prevention, Atlanta, Ga., \\ ${ }^{\mathrm{c} C e n t e r}$ for Health Research, Kaiser Permanente Northwest, Portland, Oreg., ${ }^{\mathrm{d}}$ National Center on Birth \\ Defects and Developmental Disabilities, Centers for Disease Control and Prevention, Atlanta, Ga., USA; \\ eInstitute of Neutraceuticals and Functional Foods, Laval University, Quebec, Que., Canada; ${ }^{\mathrm{f} D e p a r t m e n t}$ of \\ Bioethics, Case Western Reserve University, Cleveland, Ohio, USA; ${ }^{9}$ Biomedical Ethics Unit, McGill University, \\ Montreal, Que., Canada
}

\section{Key Words}

Direct access testing • Factor V Leiden • Nutrigenomics •

Pharmacogenomics

\begin{abstract}
Background: Recent years have seen increased concern about direct-to-consumer (DTC) genetic testing (i.e., the sale and use of genetic tests without involving a health care provider). Numerous professional organizations have developed policies in this area. However, little systematic evidence exists to inform public policy about these tests. Methods: We conducted a systematic search to identify genetic tests that are sold DTC without involving a health care provider. We evaluated the practices of companies offering DTC genetic tests for risk of thrombosis using criteria from multiple sources and a minimal set of key practices. $\boldsymbol{R} \boldsymbol{e}$ sults: We identified 84 instances of currently available health-related DTC genetic tests sold on 27 Web sites; the most common were for pharmacogenomics (12), risk of thrombosis (10), and nutrigenomics (10). For the DTC genetic tests for risk of thrombosis, we found low adherence to recommendations. Online information was frequently in-
\end{abstract}

complete and had low agreement with professional recommendations. Conclusion: Our findings document the rapid growth in the availability of health-related DTC genetic tests and highlight the need to improve the delivery of DTC genetic tests. A major implication of this study is the need for the scientific and medical community to develop consistent recommendations to increase their impact.

Copyright $\odot 2008$ S. Karger AG, Basel

Direct-to-consumer (DTC) genetic testing is the sale and use of genetic tests without the involvement of a health care provider. This activity has recently gained the attention of many professional organizations [1-3]. Some of the concerns fueling the growing debate about DTC genetic tests [4-7] are the perception of rapid increases in their availability over the Internet and the sale of questionable products that have received widespread atten-

The findings and conclusions in this report are those of the author(s) and do not necessarily represent the official position of the Centers for Disease Control and Prevention.

\section{KARGER}

Fax +41613061234 E-Mail karger@karger.ch www.karger.com
Katrina A.B. Goddard

Center for Health Research

Kaiser Permanente Northwest, 3800 N. Interstate Avenue

Portland, OR 97227 (USA)

Tel. +1 503335 6353, Fax +1 503335 2428, E-Mail katrina.ab.goddard@kpchr.org 
tion in the popular media $[8,9]$. In addition, investigations on the impact of DTC advertisements of pharmaceuticals and medical products suggest that such advertisements may be more harmful than beneficial to consumers [10-13].

Although anecdotal evidence suggests that the concerns raised may be valid in at least some instances, systematic research is needed to document the extent of the problem and the areas requiring particular scrutiny. In 2003 Gollust and coworkers [14] provided the most current assessment of health-related DTC genetic tests; these investigators identified 14 distinct health-related genetic testing products. The recent recommendations published in the ASHG policy statement [3] provide an important tool or yardstick to measure the performance of these tests and provide valuable and much-needed information about their delivery. In addition, an evaluation of DTC genetic tests in the context of recommended practices will inform us about the extent to which current recommendations are followed, if they exist, and it will provide insight into the comprehensiveness and utility of available recommendations.

To inform the public policy debate surrounding these tests, we collected observations on Web sites offering health-related DTC genetic tests to assess the content, quality, and quantity of DTC advertising and sale of health-related genetic tests. We examined to what extent current practices adhere to related professional recommendations or federal regulatory requirements. To document this adherence, we evaluated the content of $5 \mathrm{Web}$ sites that distributed a genetic test for assessment of the risk of thrombosis. This subset was selected because the genetic tests were relatively uniform in terms of the genes and polymorphisms that were included as part of the test, and therefore could be more accurately compared with each other. We evaluated practices such as providing preand post-test counseling, laboratory accreditations, methods of reporting test results, privacy policies, and cost. We compared indications for testing, presentation of risks and benefits, and the limitations of testing with existing practice recommendations from professional organizations for risk of thrombosis.

\section{Material and Methods}

Resources Used to Identify Health-Related DTC Genetic Tests

To identify health-related genetic tests that were sold DTC (vs. advertised DTC) (table 1), we used 3 sources of information: the scientific literature, gray literature, and professional contacts. We used PubMed to identify sources through the scientific literature using key search terms including direct to consumer and direct access in combination with terms such as DNA/gene/genetic/test/ testing. To search the gray literature, we followed the strategy of Gollust and colleagues [14] by employing Google to identify genetic tests sold DTC; we used key search terms including genetics or DNA and test or testing combined with home, kit, disease, or service. Because so many documents (over a million) were identified by this method, we reviewed only a subset of those documents (approximately the first few 100 at the top of the list), which is a limitation of our study. This search yielded news articles, Web sites maintained by consumer advocacy groups, diagnostic manufacturer, laboratory, or test distributor Web sites, and scientific articles. Documents were read to extract potential novel healthrelated DTC genetic tests. Based on a report by Chin et al. [15], we also used Lexis-Nexis ${ }^{\circledR}$ (www.lexisnexis.com) which they deemed high-utility or very productive in identifying genetic tests. Finally, we solicited information from professional contacts. These searches were conducted in spring 2007.

\section{Definition of Health-Related DTC Genetic Tests}

Using the sources identified above, we applied several definitions, conventions, and criteria to compile a final list of healthrelated DTC genetic tests. First, we used the definition of genetic test developed by the Secretary's Advisory Committee on Genetic Testing (SACGT): 'A genetic test is an analysis performed on human DNA, RNA, genes, and/or chromosomes to detect heritable or acquired genotypes, mutations, phenotypes, or karyotypes that cause or are likely to cause a specific disease or condition. A genetic test also is the analysis of human proteins and certain metabolites, which are predominantly used to detect heritable or acquired genotypes, mutations, or phenotypes' [16].

Thus, a genetic test could refer to an inherited or a somatic genetic alteration, and it could include a test that detects the alteration using either molecular or biochemical biomarkers in the assay. Furthermore, it could be a test of a single alteration, or it could refer to a panel of markers within the same gene or in different genes. We designated a genetic test as health related if its purpose was to predict risk of disease, screen for disease, direct clinical management, identify carriers, or establish prenatal diagnoses, clinical diagnoses, or prognoses in individual people or families.

We designated a genetic test as available DTC if we were able to identify an online mechanism to order the test (e.g., Web site, phone number or address, or a form to be printed and faxed or mailed) by consumers in the US without the involvement of a health care professional. We excluded all instances where the test was not yet available, where the Web site link no longer existed (as of May 2007), and where we could not determine how to order the test. Our search criteria were specifically designed to exclude tests sold through some other mechanism (e.g., drugstore, grocery store, spa, exercise facility, or catalog), but not available for sale over the Internet. Each element we identified was a unique combination of a test distributor (i.e., a company providing a Web site where the test could be purchased) and a health-related DTC genetic test. Thus, a test that was offered by more than one distributor was included more than once. If a test distributor offered more than one genetic test that could be ordered individually or in a bundle, we included only the individual tests and did not include the bundle separately. We did not include companies that manufactured a test but did not provide a method to directly order the 
Table 1. Eighty-four instances of health-related DTC genetic tests sold over the Internet in the US as of August, 2007

\begin{tabular}{|c|c|c|c|}
\hline Application & Company name & Test name & Cost (USD) \\
\hline \multirow[t]{6}{*}{ Fetal sex (5) } & & & $215-390$ \\
\hline & Acu-Gen Biolab & Baby Gender Mentor & \\
\hline & Consumer Genetics & Pink or Blue Test & \\
\hline & GeneTree & Pink or Blue Test & \\
\hline & DNAplus & Fetal Cell/DNA Prenatal Gender Test & \\
\hline & Paragon Genetics & Non-Invasive Baby Gender Predictor & \\
\hline \multicolumn{3}{|c|}{ Pregnancy complications (3) } & $350-995$ \\
\hline & DNA Direct & Infertility - Male/Female & \\
\hline & DNA Direct & Recurrent Pregnancy Loss Male/Female & \\
\hline & MyGenome & Pregnancy Risk & \\
\hline \multicolumn{3}{|c|}{ Lifestyle factors (6) } & $100-258$ \\
\hline & Consumer Genetics & Heart Attack Risk & \\
\hline & CyGene Direct & Athletic Performance & \\
\hline & Genetic Technologies & Athletic Performance & \\
\hline & Dermagenetics & Dermagenetics & \\
\hline & GeneLink & Dermagenetics & \\
\hline & G-nostic & Smoking Cessation & \\
\hline \multicolumn{3}{|c|}{ Nutrigenomics (10) } & $100-625$ \\
\hline & Carolyn Katzin & The DNA Diet & \\
\hline & Genelex & DNA Diet & \\
\hline & Genelex & Nutritional Genetic Panel & \\
\hline & GeneLink & GeneLink Nutragenetic Profile & \\
\hline & Interleukin Genetics & Gensona General Nutrition Genetic Test & \\
\hline & MarketAmerica & GeneSNP & \\
\hline & Quixtar & Gensona General Nutrition & \\
\hline & Salugen & Genoscore DNA Test & \\
\hline & Sciona & MyCellf & \\
\hline & Suracell & Personal DNA Analysis Profile & \\
\hline \multicolumn{3}{|c|}{ Pharmacogenomics (12) } & $250-2,500$ \\
\hline & DNA Direct & Drug Metabolism & \\
\hline & Genelex & Extended DNA Drug Reaction Panel & \\
\hline & Genelex & Drug Reaction Panel & \\
\hline & Genelex & Warfarin (Coumadin) Target Dose Safety Test & \\
\hline & DNA Direct & Tamoxifen (CYP2D6) & \\
\hline & Kimball Genetics & Warfarin DoseAdvise Genetic Test & \\
\hline & MyGenome & Drug Sensitivities & \\
\hline & PGxHealth & PGxPredict: CLOZAPINE & \\
\hline & PGxHealth & PGxPredict: RITUXIMAB & \\
\hline & PGxHealth & PGXPredict: WARFARIN & \\
\hline & Signature Genetics & The All Inclusive Report & \\
\hline & Signature Genetics & The Drug Gene Report & \\
\hline \multicolumn{3}{|c|}{ Thrombosis $(10)^{\circ}$} & $90-380$ \\
\hline & CyGene Direct & Thrombosis DNA Analysis & \\
\hline & DNA Direct & Factor V Leiden & \\
\hline & Health Tests Direct & Factor V Leiden & \\
\hline & HealthCheckUSA & Factor V DNA Test & \\
\hline & HealthCheckUSA & Factor V R2 DNA Test & \\
\hline & HealthCheckUSA & Prothombin (Factor II) DNA Test & \\
\hline & Kimball Genetics & Factor V Leiden DNA Test & \\
\hline & Kimball Genetics & Factor V R2 DNA Test & \\
\hline & Kimball Genetics & Prothrombin (Factor II) DNA Test & \\
\hline & MyGenome & Thrombosis & \\
\hline
\end{tabular}


Table 1 (continued)

\begin{tabular}{|c|c|c|c|}
\hline Application & Company name & Test name & Cost (USD) \\
\hline \multicolumn{3}{|c|}{ Hemochromatosis (5) } & \multirow[t]{6}{*}{$195-560$} \\
\hline & DNA Direct & Hemochromatosis & \\
\hline & Genelex & Hemochromatosis DNA Test & \\
\hline & Health Tests Direct & Hereditary Hemochromatosis & \\
\hline & HealthCheckUSA & Hereditary Hemochromatosis & \\
\hline & Kimball Genetics & Hemochromatosis DNA Test & \\
\hline \multicolumn{3}{|c|}{ Chronic diseases (14) } & \multirow[t]{15}{*}{$90-3,456$} \\
\hline & Graceful Earth & Alzheimer Test/ApoE & \\
\hline & Kimball Genetics & ApoE Genotype Test & \\
\hline & MyGenome & Alzheimer Disease/ApoE & \\
\hline & DNA Direct & Breast and Ovarian Cancer/BRCA1 \& BRCA2 & \\
\hline & Health Tests Direct & Breast Cancer/HER2 & \\
\hline & DNA Direct & PreGen-Plus Colon Cancer Screening & \\
\hline & Kimball Genetics & Coronary Artery Disease/MTHFR DNA Test & \\
\hline & DNA Direct & Diabetes/deCODE T2 & \\
\hline & CyGene Direct & Glaucoma \& Macular Degeneration DNA Analysis & \\
\hline & Interleukin Genetics & Gensona Heart Health Genetic Test & \\
\hline & MyGenome & Cardiovascular Disease & \\
\hline & Quixtar & Gensona Heart Health & \\
\hline & CyGene Direct & Osteoporosis DNA Analysis & \\
\hline & MyGenome & Osteoporosis & \\
\hline \multicolumn{3}{|c|}{ Pediatric conditions $(7)$} & \multirow[t]{8}{*}{$260-1,266$} \\
\hline & DNA Direct & Cystic Fibrosis & \\
\hline & Health Tests Direct & CF Carrier Screen & \\
\hline & Kimball Genetics & Cystic Fibrosis DNA Test & \\
\hline & Kimball Genetics & Fragile X DNA Test & \\
\hline & Kimball Genetics & Fragile X-Associated Tremor/Ataxia Syndrome Test & \\
\hline & DNA Direct & Ashkenazi Jewish Carrier Screening & \\
\hline & Kimball Genetics & Tay-Sachs Disease DNA Test & \\
\hline \multicolumn{3}{|c|}{ Immune-related conditions (6) } & \multirow[t]{7}{*}{$99-445$} \\
\hline & Kimball Genetics & Ankylosing Spondylitis/HLA-B27 DNA Test & \\
\hline & Genelex & Celiac Disease DNA Test & \\
\hline & HealthCheckUSA & Celiac Disease DNA Test & \\
\hline & Kimball Genetics & Celiac Disease DNA Test & \\
\hline & DNA Direct & $\alpha 1$-Antitrypsin Deficiency & \\
\hline & HIVmirror & HIV-1 Progression/CCR5 and HIV-1 Progression & \\
\hline \multicolumn{3}{|c|}{ Other health-related tests (6) } & \multirow[t]{7}{*}{$160-5,400$} \\
\hline & PGxHealth & The Familion Test/Cardiac Channelopathies & \\
\hline & CyGene Direct & Metabolic Health Assessment & \\
\hline & Genelex & Narcolepsy DNA test & \\
\hline & Kimball Genetics & Narcolepsy DNA Test & \\
\hline & Genelex & Periodontal Disease DNA Test & \\
\hline & Kimball Genetics & PST Genetic Test: Susceptibility to Peridontal Disease & \\
\hline
\end{tabular}

test from their Web site. We also excluded laboratories that performed the genetic test but did not provide a method for consumers to directly order the test.

Evaluation of Web Site Practices

Previous reports of laboratory practices in the area of genetic testing, especially those including questions about DTC services and quality of reporting, were used as a starting point to develop survey questions [17-19]. We created data collection forms to systematically abstract information from each Web site. Two abstractors (K.G., J.R.) independently collected data via the data collection forms using the information provided on each Web site. The information from the data collection forms was coded (typically as present or absent) and entered into an electronic file, and it was compared for consistency across abstractors. Items that were inconsistent were resolved through discussion with a third 
Table 2. Interpretation of recommendations presented in supplementary table 1 with respect to the sets of practices evaluated in this study

$\begin{array}{llllll}\text { ASHG } & \begin{array}{l}\text { ACMG } \\ (2008)\end{array} & \text { NSGC } & \text { FDA/FTC }^{a} & \begin{array}{l}\text { Set 1 } \\ \text { practices }\end{array} & \begin{array}{l}\text { Set 2 } \\ \text { practices }\end{array}\end{array}$

General information

disclose which genes are tested

disclose which polymorphisms are tested

Pre-test counseling

provide guidance on indications for testing

describe benefits of testing

describe risks of testing

Laboratory

laboratory is CLIA certified

Post-test counseling provide information on test limitations provide information on clinical validity allow consumer to call with questions refer consumer to their doctor assist consumer with obtaining a doctor refer to another source of information

Privacy protections provide written privacy policy Total practices

\begin{tabular}{|c|c|c|c|c|c|}
\hline & & & & $\begin{array}{l}+ \\
+\end{array}$ & + \\
\hline & + & & & + & + \\
\hline+ & + & & + & + & + \\
\hline+ & & & + & + & + \\
\hline+ & + & + & + & + & + \\
\hline+ & + & + & + & + & \\
\hline \multirow[t]{5}{*}{+} & & + & & + & \\
\hline & & & & + & \\
\hline & & + & + & + & + \\
\hline & & + & & + & \\
\hline & & + & & + & \\
\hline+ & & & + & + & + \\
\hline 6 & 4 & 6 & 6 & 13 & 7 \\
\hline
\end{tabular}

${ }^{\text {a }}$ Recommendations in the FTC fact sheet were consumer-oriented rather than company-oriented.

evaluator (C.M.). Our report of company practices refers to companies by code only. Data collection was approved by the human research protection offices at the Centers for Disease Control (CDC) as public health practice (and not research) after review for determination of research status.

\section{Identification of Recommended Practices and Guidelines}

We used several published and professional sources to establish 2 sets of criteria for the analysis of the practices of test distributors. Because there are no definitive standards of practice for DTC genetic testing, the first set of criteria was based on a group of published recommendations: ASHG (American Society of Human Genetics) recommendations, ACMG (American College of Medical Genetics) recommendations [1], a position statement of DTC genetic testing from the National Society of Genetic Counselors (NSGC) [2], and a publication by Reich and coworkers [20] that specifically addresses recommendations for counseling for inherited thrombophilia in the traditional medical framework. In the absence of publications from the Food and Drug Administration (FDA) and Federal Trade Commission (FTC) explicitly relating to regulation of DTC genetic testing, we considered publications on broadcast [21] or print [22,23] advertisements aimed directly to consumers for prescription medications or for dietary supplements [24]. We also considered a FTC fact sheet on DTC genetic testing, although these recommendations were consumer-oriented rather than company-oriented [25]. From these sources, we identified 13 potential practices (Set 1) for healthrelated DTC genetic test distributors (we should note that no single source recommends all 13 practices) (table 2). Because this set of practices was subjective, we used a minimal set of 7 practices (Set 2) as the second set of criteria (table 2). The practices in Set 2 were identified as (1) typical requirements for disclosure of information, according to FDA regulations on DTC print advertisements for prescription medications $[22,23]$ or for dietary supplements [24], and (2) practices that were observed for at least 4 of the 5 test distributors evaluated in our analysis. Further details regarding the practices recommended by these organizations are provided in supplementary table 1 (for online supplementary material, see www.karger.com/doi/10.1159/000176794) and table 3.

In the context of genetic tests for thrombophilias (tests that relate genetic variations to blood clotting disorders), 2 consensusbased recommendations (vs. evidence-based recommendations) outline accepted indications for testing, one published by the ACMG [26] and the other presented at the College of American Pathologists (CAP) Consensus Conference XXXVI [27]. These recommendations, in addition to other statements by the ACMG $[1,26]$, provided direction on accepted indications for testing, risks and benefits of testing, and reporting guidelines.

\section{Statistical Analysis}

Data was coded and tabulated, and inter-rater agreement was assessed by computing the proportion agreement and kappa statistics using SAS (SAS Institute, Cary, N.C., USA). 
Table 3. Logistics and practices of direct-to-consumer companies offering genetic tests for thrombosis

\begin{tabular}{|c|c|c|c|c|c|c|c|}
\hline & \multirow{2}{*}{$\begin{array}{l}\text { Set } 1 \\
\text { prac- } \\
\text { tices }^{\text {a }}\end{array}$} & \multirow{2}{*}{$\begin{array}{l}\text { Set } 2 \\
\text { prac- } \\
\text { tices }^{b}\end{array}$} & \multicolumn{5}{|c|}{ DTC company } \\
\hline & & & A & $\mathrm{B}$ & $\mathrm{C}$ & $\mathrm{E}$ & $\mathrm{F}$ \\
\hline \multicolumn{8}{|l|}{ Logistics } \\
\hline Method of sample collection & & & cheek & cheek & blood & blood & blood \\
\hline Length of time to obtain test result (in days) & & & NA & $7-10$ & & NA & $4-10$ \\
\hline How is report delivered? & & & Web site & Web site & letter & letter & $\begin{array}{l}\text { letter, fax, } \\
\text { or Web site }\end{array}$ \\
\hline Who is report delivered to? & & & consumer & consumer & $\begin{array}{l}\text { consumer } \\
\text { and doctor }\end{array}$ & consumer & consumer \\
\hline \multicolumn{8}{|l|}{ Practices } \\
\hline \multicolumn{8}{|l|}{ General information } \\
\hline disclose which genes are tested & + & + & yes & yes & yes & yes & yes \\
\hline disclose which polymorphisms are tested & + & & yes & no & yes & yes & no \\
\hline \multicolumn{8}{|l|}{ Pre-test counseling } \\
\hline provide guidance on indications for testing & + & + & yes & yes & yes & no & yes \\
\hline describe benefits of testing & + & + & yes & yes & no & no & no \\
\hline describe risks of testing & + & + & no & yes & no & no & no \\
\hline \multicolumn{8}{|l|}{ Laboratory } \\
\hline laboratory is CLIA certified ${ }^{\mathrm{c}}$ & + & + & yes & yes & yes & yes & no \\
\hline \multicolumn{8}{|l|}{ Post-test counseling } \\
\hline provide sample report of test result & & & yes & yes & no & no & no \\
\hline provide information on test limitations & + & & no & no & no & no & no \\
\hline provide information on clinical validity & + & & no & no & no & no & no \\
\hline allow consumer to call with questions & + & & no & yes & yes & no & no \\
\hline refer consumer to their doctor & + & + & yes & yes & yes & no & no \\
\hline assist consumer with obtaining a doctor & + & & no & no & no & yes & no \\
\hline refer to another source of information & + & & yes & no & no & yes & no \\
\hline \multicolumn{8}{|l|}{ Privacy protections } \\
\hline provide written privacy policy & + & + & yes & yes & no & yes & yes \\
\hline Total Set 1 practices & 13 & - & 8 & 8 & 6 & 6 & 3 \\
\hline Total Set 2 practices & - & 7 & 6 & 7 & 4 & 3 & 3 \\
\hline
\end{tabular}

\footnotetext{
a Set 1 practices identified from recommendations including the ASHG policy statement, the NSGC position statement, the ACMG policy statement, FTC recommendations for DTC advertisements, and a publication by Reich and co-workers [20].

${ }^{b}$ Set 2 practices are defined as (1) required by FTC recommendations for DTC advertisements or (2) practices used by most test distributors.

${ }^{c}$ We assessed whether there was a statement that a CLIA certified laboratory was used, but we could not confirm these statements.
}

\section{Results}

\section{Scan for Health-Related DTC Genetic Tests}

We identified 84 instances of health-related DTC genetic tests that were being sold on 27 distinct test distributor Web sites as of August 2007 (table 1). These instances corresponded to 53 unique tests, because some were sold by more than one distributor. Each Web site contained between 1 and 15 health-related DTC genetic testing products. These estimates should be considered a lower bound on the number of currently available health- related DTC genetic tests, as although we carefully confirmed each observed instance, our scans could have missed some sites.

Most of the test distributors were located in the US, with 3 from Canada, the United Kingdom, and Australia (online supplementary table 2). The most common healthrelated DTC genetic tests were for pharmacogenomics (tests that relate genetic variations to the response to drugs) (12), thrombosis (tests that relate genetic variations to clotting disorders) (10), nutrigenomics (tests using information on diet, lifestyle, and genetics to inform recom- 
Table 4. Genes and polymorphisms evaluated in DTC genetic tests for thrombosis

\begin{tabular}{|c|c|c|c|c|}
\hline \multirow[t]{2}{*}{ DTC company } & \multicolumn{4}{|c|}{ Gene (polymorphism) ${ }^{\mathrm{a}}$} \\
\hline & $\begin{array}{l}\text { factor V Leiden } \\
\text { (R506Q) }\end{array}$ & $\begin{array}{l}\text { factor V R2 } \\
\text { (H1299R) }\end{array}$ & $\begin{array}{l}\text { prothrombin } \\
\text { (factor II) }\end{array}$ & $M T H F R^{\mathrm{b}}$ \\
\hline A & $+(\mathrm{G} 1691 \mathrm{~A})$ & & $+(\mathrm{G} 20210 \mathrm{~A})$ & $+(\mathrm{C} 667 \mathrm{~T}, \mathrm{~A} 1298 \mathrm{C})$ \\
\hline $\mathrm{B}$ & $+(\mathrm{G} 1691 \mathrm{~A})$ & & + & \\
\hline $\mathrm{C}$ & $+(\mathrm{G} 1691 \mathrm{~A})$ & + & + & $+(\mathrm{C} 667 \mathrm{~T}, \mathrm{~A} 1298 \mathrm{C})$ \\
\hline $\mathrm{E}$ & $+(\mathrm{G} 1691 \mathrm{~A})$ & & & \\
\hline $\mathrm{F}$ & $+(\mathrm{G} 1691 \mathrm{~A})$ & + & + & \\
\hline
\end{tabular}

\footnotetext{
${ }^{a}+$ indicates that a genetic test for this gene is present on the website. If the + is followed by parentheses, this indicates that the specific polymorphisms were also mentioned on the Web site. Otherwise, the Web site only mentions the gene, without indicating which polymorphisms within that gene are tested.

${ }^{\mathrm{b}} M T H F R=$ Methylenetetrahydrafolate reductase.
}

mendations on changes in behaviors, diet, or specific nutritional supplements) (10), fetal sex (5), and hereditary hemochromatosis (5). Prices ranged from USD 90 to 5,400 .

About one-third of health-related DTC genetic tests were offered in both the DTC and typical clinical settings. Tests offered in both settings include those for pediatric conditions (such as Tay-Sachs disease, fragile $\mathrm{X}$ syndrome, and cystic fibrosis) and for chronic disorders (such as BRCA1/2 testing for risk of breast or ovarian cancer, HER 2 testing for recurrence of breast cancer, thrombosis risk, and hereditary hemochromatosis). In contrast, the majority $(\sim 66 \%)$ of the tests was offered primarily outside the framework of traditional clinical medicine and included genetic tests such as prediction of fetal sex, dermagenetics (tests using genetic information to inform recommendations on skin care products), nutrigenomics, and prediction of smoking cessation.

\section{Survey of Company Practices}

Company practices were evaluated for only a subset of health-related genetic tests that included those for thrombosis risk. This subset was selected because (1) the genetic tests were relatively uniform in terms of the genes and polymorphisms that were included as part of the test, (2) there are existing professional recommendations regarding their use, and (3) thrombosis risk is a potentially serious and life-threatening condition. These factors improve our ability to compare the company practices with each other. Thrombosis is a multifactorial disease with both genetic and acquired risk factors. The factor $\mathrm{V}$ Leiden (R506Q) mutation (OMIM (Online Mendelian
Inheritance in Man): 227400), associated with increased resistance to the anticoagulant effects of activated protein $\mathrm{C}$, is the most common prothrombotic variant. About $5 \%$ of Caucasians are carriers, and the increase in risk for venous thromboembolism is $3-8 \%$ and $50-80 \%$ for heterozygous and homozygous carriers, respectively [28, 29]. Anecdotally, the genetic test for the factor V Leiden mutation is one of the tests most commonly ordered by clinicians. A G-to-A transition at position 20210 of the prothrombin gene (OMIM: 176930), present in 2-3\% of Caucasians, is associated with elevation in blood prothrombin concentrations and with a 3 -fold increased risk for venous thromboembolism [30]. Some studies have demonstrated that polymorphisms in other genes in coagulation pathways, including the methylenetetrahydrofolate reductase (MTHFR) C677T mutation (OMIM: 607093), are associated with small elevations in risk of thrombosis [31].

The 10 tests for risk of thrombosis that were offered in the DTC setting were relatively homogeneous, including 7 tests for the same mutation, factor V Leiden (R506Q). The other 3 tests included evaluation of prothrombin (G20210A), the factor V R2 (H1299R or A4070G) mutation, and MTHFR (C677T) (table 4). The 10 tests were offered DTC by 6 different companies (table 1). One of the tests (and companies) was eliminated from further consideration because the information provided on the Web site was inadequate to include in this analysis and we did not receive a response to an e-mail query for more information.

The test distributors that we evaluated generally used fewer than 9 of the 13 practices in Set 1, ranging between 
Table 5. Indications of factor V Leiden or prothrombin (factor II) genetic testing

\begin{tabular}{|c|c|c|c|c|c|c|c|}
\hline \multirow[t]{2}{*}{ Indications $^{\mathrm{a}}$} & \multirow[t]{2}{*}{$\mathrm{ACMG}^{\mathrm{b}}$} & \multirow[t]{2}{*}{$\mathrm{CAP}^{\mathrm{c}}$} & \multicolumn{5}{|c|}{ DTC company ${ }^{\mathrm{d}}$} \\
\hline & & & $\mathrm{A}$ & $\mathrm{B}$ & $\mathrm{C}$ & $\mathrm{E}$ & $\mathrm{F}$ \\
\hline A first VTE before age 50 years & $\mathrm{S}$ & S & - & S & - & - & - \\
\hline A first unprovoked VTE at any age & - & $\mathrm{S}$ & - & - & - & - & - \\
\hline A history of recurrent VTE & $\mathrm{S}$ & S & - & S & - & - & - \\
\hline Venous thrombosis at unusual sites & $\mathrm{S}$ & S & - & $\mathrm{S}$ & - & - & - \\
\hline VTE during pregnancy & $\mathrm{S}$ & $\mathrm{S}$ & - & S & - & - & - \\
\hline VTE during the puerperium & - & $\mathrm{S}$ & - & S & - & - & - \\
\hline VTE associated with use of OC & $\mathrm{S}$ & S & - & S & - & - & - \\
\hline VTE associated with HRT & - & S & - & M & - & - & - \\
\hline Relatives of individuals with venous thrombosis under age 50 & $\mathrm{~S}$ & - & - & - & - & - & - \\
\hline A first VTE in an individual with a first degree family member with VTE before age 50 & $S^{e}$ & S & - & $\mathrm{S}^{\mathrm{e}}$ & - & - & - \\
\hline Women with unexplained fetal loss after 10 weeks gestation & M & S & - & - & S & - & - \\
\hline Female smokers younger than age 50 years with an MI or stroke & $S$ & $\mathrm{M}$ & - & - & - & - & - \\
\hline \multicolumn{7}{|l|}{ Selected women with unexplained severe preeclampsia, placental abruption, } & - \\
\hline A first VTE related to the use of tamoxifen or other SERMs & - & $\mathrm{M}$ & - & - & - & - & - \\
\hline \multicolumn{7}{|l|}{ Individuals $>50$ years with a first provoked VTE in the absence of malignancy or } & - \\
\hline Asymptomatic adult relatives of probands with a known factor V Leiden mutation & M & - & - & M & - & - & - \\
\hline $\begin{array}{l}\text { Asymptomatic adult relatives of probands with a known factor V Leiden mutation, } \\
\text { especially those with a strong family history of VTE at a young age ( }<50 \text { years) }\end{array}$ & - & M & - & - & S & - & - \\
\hline \multicolumn{8}{|l|}{ Asymptomatic female relatives of probands with a known factor $\mathrm{V}$ Leiden mutation } \\
\hline who are pregnant or are considering pregnancy or OC use & $\mathrm{M}$ & $\mathrm{M}$ & - & - & - & - & - \\
\hline Women with recurrent pregnancy loss & $\mathrm{M}$ & - & - & M & $\mathrm{S}$ & - & - \\
\hline Individuals with any family member with VTE & - & - & $\mathrm{S}$ & M & S & - & $\mathrm{S}$ \\
\hline Anyone & - & - & $\mathrm{M}$ & - & - & - & - \\
\hline Personal history of VTE & - & - & - & - & S & - & $\mathrm{S}$ \\
\hline Personal history of pulmonary embolism & - & - & - & - & $\mathrm{S}$ & - & $\mathrm{S}$ \\
\hline Personal history of TIA or premature stroke & - & - & - & - & S & - & $\mathrm{S}$ \\
\hline Personal history of peripheral vascular disease & - & - & - & - & $\mathrm{S}$ & - & - \\
\hline Personal history of cerebral vein thrombosis & - & - & - & - & S & - & $\mathrm{S}$ \\
\hline Women with premature MI & - & - & - & - & $\mathrm{S}$ & - & $\mathrm{S}$ \\
\hline \multicolumn{8}{|l|}{ Prior to major surgery, pregnancy, OC use, or HRT if there is a personal or family } \\
\hline history of thrombosis & - & - & - & M & $\mathrm{S}$ & - & - \\
\hline \multicolumn{8}{|l|}{ Presence of another known genetic hypercoagulability in an individual with a } \\
\hline history of thrombosis & - & - & - & - & $\mathrm{S}$ & - & - \\
\hline Previous finding of activated protein $\mathrm{C}$ resistance by lab analysis & - & - & - & - & S & - & - \\
\hline
\end{tabular}

${ }^{\mathrm{a}} \mathrm{HRT}=$ Hormone replacement therapy; $\mathrm{MI}=$ myocardial infarction; $\mathrm{OC}=$ oral contraceptives; SERMs = selective estrogen receptor modulators; TIA = transient ischemic attack; VTE = venous thromboembolism.

b American College of Medical Genetics consensus recommendation published in Grody et al. [26].

${ }^{c}$ College of American Pathologists consensus recommendation published in Press et al. [27].

d $\mathrm{S}$ = Testing should be performed; $\mathrm{M}$ = testing may be considered; - = the indication was not specifically mentioned.

e The wording of the recommendation specified a 'strong family history', which was not defined.

3 and 8 (table 3 ). The practices least likely to be used were (1) disclosure of the risks and limitations of testing and (2) information on the clinical validity of the test. The practices in Set 2 contain disclosures typically required by the FDA for products other than genetic tests (in the absence of FDA guidance explicitly for DTC genetic tests), including risks and benefits of testing and 'adequate provision ... for dissemination of the approved or permitted package labeling', such as referral to a physician for more information. Furthermore, the FDA typically requires 'fair balance' in the portrayal of risks and benefits of the product. Of the 7 practices in Set 2, only company B im- 
Table 6. Risks, benefits, and limitations of factor V Leiden testing

$\mathrm{ACMG}^{\mathrm{b}} \mathrm{CAP}^{\mathrm{c}}$ DTC company ${ }^{\mathrm{d}}$

A $\quad$ B $\quad$ C $\quad$ E $\quad$ F

Benefits of factor V Leiden testing ${ }^{\mathrm{a}}$

identification of high-risk patients who could benefit from long-term anticoagulant therapy +

identification of high-risk patients who could benefit from aggressive prophylaxis in temporary periods of high thrombotic risk

opportunity to counsel at-risk family members about risks, signs, and symptoms of VTE

future decisions regarding HRT could depend on genotype

future decisions regarding management of pregnancy complications could depend on genotype

future decisions regarding $\mathrm{OC}$ use could depend on genotype

to have greater control over your health care

to provide you with tools to live a longer, healthier life

future decisions regarding health-enhancing strategies could depend on genotype

future decisions regarding lifestyle changes could depend on genotype

provide a customized risk assessment

Risks and limitations of factor V Leiden testing

test does not predict thrombosis with certainty

implications for other family members

possibility of genetic discrimination

positive test results could lead to overly aggressive anticoagulation in situations with relatively low thrombotic risk

individual could have increased risk for thrombophilia from another cause not detected by this test

individuals could have psychological, medical, social, and reproductive implications due to testing, but counseling is not needed

the cost of testing may not be covered by insurance

the results of testing may not change the medical care or lifestyle of the subject

results of test could reveal non-paternity

${ }^{\mathrm{a}} \mathrm{HRT}=$ Hormone replacement therapy; $\mathrm{OC}=$ oral contraceptive; VTE = venous thromboembolism.

${ }^{b}$ American College of Medical Genetics consensus recommendation published in Grody et al. [26].

${ }^{c}$ College of American Pathologists consensus recommendation published in Press et al. [27].

$\mathrm{d}_{+}=$The risk or benefit was specifically mentioned; $-=$the risk or benefit was not mentioned.

plemented all 7 (table 3), with the other companies implementing between 3 and 6 . Only company B provided information on both risks and benefits of testing. Information on test limitations and information on clinical validity were the least likely practices to be implemented. We note that this information is also frequently unavailable for genetic tests that are marketed to providers. We evaluated the presence or absence of particular practices on the Web sites, but that does not speak to the accuracy of the information provided. Therefore, we evaluated the accuracy of information provided on the sites on indications for testing, risks, and benefits by using published guidance documents for these tests.

The 2 professional organizations (ACMG, CAP) had good agreement for the recommended indications for testing (proportion agreement $=0.73)($ table 5$)$. In contrast, the company Web sites demonstrated relatively poor agreement with the recommended indications from the professional organizations. In general, the Web sites used simplified language that tended to broaden the class of persons for whom testing was indicated. Some examples of this pattern include 'individuals with any family member with venous thromboembolism (VTE)' (from the Web site) vs. 'relatives of individuals with venous thrombosis under age 50' (from the recommendation), or 'women with premature MI' (myocardial infarction) (from the Web site) vs. 'female smokers younger than age 50 years with a MI or stroke' (from the recommendation), or 'a personal history of VTE' (from the Web site) vs. 'a first VTE before age 50 years' (from 
Table 7. Inter-rater agreement on initial classification in each table

\begin{tabular}{|c|c|c|c|c|c|}
\hline & $\begin{array}{l}\text { Proportion } \\
\text { agreement }\end{array}$ & Kappa statistic (CI) & \multicolumn{3}{|c|}{$\begin{array}{l}\text { Class-specific } \\
\text { proportion agreement }\end{array}$} \\
\hline Table $3^{\mathrm{a}}$ & 0.676 & & & & \\
\hline Table 4 - Genes & 0.917 & $0.86(0.67,1.00)$ & $0.86(\mathrm{Y})$ & $0.75(\mathrm{~N})$ & 1.00 (NA) \\
\hline Table 4 - Polymorphisms & 0.933 & $0.89(0.75,1.00)$ & $0.92(\mathrm{Y})$ & $0.60(\mathrm{~N})$ & 0.93 (NA) \\
\hline Table 5 - Recommendations & 0.917 & $0.86(0.75,0.98)$ & $1.00(\mathrm{~S})$ & $0.64(\mathrm{M})$ & $0.85(-)$ \\
\hline Table 5 - Web sites & 0.933 & $0.81(0.70,0.92)$ & $0.80(\mathrm{~S})$ & $0.50(\mathrm{M})$ & $0.92(-)$ \\
\hline Table 6 - Benefits, Recommendations & 0.962 & $0.92(0.77,1.00)$ & $0.91(\mathrm{Y})$ & $0.94(\mathrm{~N})$ & \\
\hline Table 6 - Benefits, Web sites & 0.846 & $0.55(0.30,0.79)$ & $0.87(\mathrm{Y})$ & $0.96(\mathrm{~N})$ & \\
\hline Table 6 - Benefits, Web sites A \& B only & 0.615 & $0.23(0.00,0.61)$ & $0.87(\mathrm{Y})$ & $0.85(\mathrm{~N})$ & \\
\hline Table 6 - Risks, Recommendations & 0.722 & $0.21(0.00,0.89)$ & $0.17(\mathrm{Y})$ & $0.71(\mathrm{~N})$ & \\
\hline Table 6 - Risks, Web sites & 0.956 & $0.78(0.48,1.00)$ & $0.67(\mathrm{Y})$ & $0.95(\mathrm{~N})$ & \\
\hline Table 6 - Risks, Web sites A \& B only & 0.889 & $0.73(0.38,1.00)$ & $0.67(\mathrm{Y})$ & $0.86(\mathrm{~N})$ & \\
\hline
\end{tabular}

$\mathrm{CI}=95 \%$ Confidence interval.

a Statistics were not computed for Table 3 because there were different response categories for each line in the table.

${ }^{\mathrm{b}} \mathrm{Y}=$ Yes; $\mathrm{S}=$ should; $\mathrm{N}=$ no; $\mathrm{M}=$ maybe; $\mathrm{NA}=$ not available; $-=$ the indication was not specifically mentioned.

the recommendation). In some instances, the Web sites provided little or no guidance about who should receive testing (e.g., companies $\mathrm{A}$ and $\mathrm{E}$ ), and in 3 out of 5 instances there was no overlap between the recommended indications from the professional organizations and the indications from the Web sites. Company $\mathrm{C}$ included only 3 of the 19 indications from the professional recommendations, and it included 10 additional indications that were not in the professional recommendations. Overall, company B had the highest agreement with the recommended indications of testing (proportion agreement $=0.6$ with ACMG and 0.7 with CAP). We note, however, that the indications for testing were difficult for us to find on this Web site, which might be a point for a future study.

We found strong agreement between the ACMG and CAP recommendations on the risks and benefits of testing (proportion agreement $=0.81$ ) (table 6). Three of the distributors, however, did not mention any risks and benefits of testing, and only one (company B) mentioned risks and benefits that overlapped with the professional recommendations. We should note that in some instances the differences in the portrayal of benefits and risks may be related to the DTC delivery mode, as the focus of the professional recommendations is the traditional delivery of genetics services through medical settings. For example, the DTC Web sites emphasized having 'greater control over your health care' and making 'lifestyle changes', which do not depend on interaction with a physician. In other instances, however, the benefits of testing mentioned by the distributor may be misleading, such as 'provide you with tools to live a longer, healthier life.'

The lack of initial classification agreement between 2 independent raters in some categories could suggest that in many instances the information provided by the distributors was not clear or easy to find, or could indicate a need to further define the criteria (table 7 ). There was good agreement $(\kappa>0.8)$ in the initial classification for disclosure of the genes and polymorphisms tested (table 4), for the indications of testing (table 5), and for the benefits of testing identified by professional organizations (table 6). In contrast, the initial classification by the 2 raters had poor agreement $(\kappa<0.8)$ for the risks and benefits identified on the Web sites and for the risks identified by the professional organizations (table 6). The level of inter-rater agreement depended on the response category. For the indications for testing (table 5), the proportion agreement was lowest when testing might be indicated (category $\mathrm{M}$ in the table). For the risks and benefits of testing (table 6), the proportion agreement was lowest in the 'yes' category ( + in the table), indicating that when statements of risks and benefits were present, they were not always clear, while it was clear when statements on risks and benefits were absent. All of the information reported in the tables reflects the consensus after review of the discrepancies by the 2 raters and a third evaluator. 


\section{Discussion}

Our results clearly demonstrate that the number of health-related DTC genetic tests is increasing at a fast pace, similar to the expansion of DTC advertising for other medical products. The availability of health-related DTC genetic tests grew from 14 tests in 2003 [14] to 84 instances (or 53 unique tests) as of August 2007. These results are not the whole story, however. Our study was restricted to health-related DTC genetic tests that were currently available, but we identified numerous products that were in the pipeline as well as products that were previously available but are no longer sold DTC (data not shown). In addition, our scans may have been incomplete, because the wealth of information on the Internet made it difficult to exhaustively search and identify these products. Finally, our analysis was restricted to healthrelated tests, while non-health-related genetic-based products may, in fact, represent the majority of DTC genetic testing that is currently available [14]. Nevertheless, our findings represent at least 53 well-documented examples of health-related DTC genetic testing products, and there could be more.

This study was also designed to evaluate the quality of information provided on the Web sites of test distributors. Compared to professional recommendations for DTC marketing of genetic tests, the information provided by the majority of distributors of thrombosis testing was either not present or uniquely different. All of the Web sites used fewer than half of the 13 practices in Set 1 identified from guidance documents by professional organizations, and only one company used all 7 practices in Set 2 (i.e., practices either typically required by the FDA or used by 4 or more Web sites). In addition, the presentation of indications for testing and of risks and benefits of testing did not generally agree with existing recommendations. The indications for testing on the Web sites tended to overstate the need for testing when viewed against the consensus-based recommendations, and most Web sites were silent regarding the risks and benefits of testing. Unfortunately, where these issues were addressed, there was not much overlap with the risks and benefits identified in the recommendations. This latter result may be at least partially explained by the DTC focus of the Web sites, which contrasts with the focus of the recommendations on the traditional medical genetics model. These results indicate discrepancies between the recommendations and current practice for some health-related DTC genetic tests, and they highlight potential problems that need further clarification by the professional or federal organizations that conduct oversight activities.

In the absence of regulation of DTC genetic testing, mechanisms for oversight are important for establishing good practices in this area, such as the recently published ASHG policy statement on DTC genetic testing [3]. However, existing policy statements by professional organizations express a variety of opinions, ranging from banning all DTC genetic testing to requiring federal regulation of all such testing. These differences may reflect the diverse perspectives of the respective organizations that have proposed such recommendations. For example, ACMG's statement places a greater emphasis on requiring pre- and post-test counseling and referrals to genetics professionals. Because of this lack of consensus, we evaluated 2 sets of criteria (table 2) and found generally low compliance with both sets among the test distributors we evaluated. A recent report by the Secretary's Advisory Committee on Genetics, Health, and Society (SACGHS) identified several gaps in existing oversight of genetic tests [32]. These recommendations include requiring proficiency testing for all non-waived laboratory tests for which materials are available to address the issue of analytic validity, that a mandatory, publicly available registry of laboratory tests should exist, that the FDA should address all laboratory tests, that a research agenda should be developed to address the issue of clinical utility, and that the educational needs of health professionals should be met, including the development of clinical decision support tools.

We should approach the interpretation of this study with caution for several reasons. First, the requirements for the type of information that should by provided by DTC genetic test distributors are not well defined, and indeed, the various professional recommendations on DTC genetic testing are inconsistent. Although we used several resources to identify recommended practices, the sets of criteria are subjective, maybe incomplete, and do not represent the view of any one organization. Second, in the case of risk for thrombosis in particular, the published recommendations are not based on a systematic review of the evidence and, instead, are based on consensus conferences and expert opinion (although a substantial literature review was included to develop the recommendations). Moreover, the recommendations may have preceded the era of DTC genetic testing to some extent, and they may not have carefully addressed all of the issues (especially risks and benefits) that are specific to the DTC mode of delivery. Therefore, the answer in terms of indications for testing, and risks, benefits, and limita- 
tions of testing remains an open question. A final concern is that the practices of only a few DTC genetic test distributors were observed, and generalization to other Web sites or products may not be appropriate. However, these distributors tended to offer more tests $($ mean $=8.2$; median $=5)$ than all 27 distributors identified in our search considered as a group $($ mean $=1.7$; median $=1$ ) and, as such, may represent the more established and experienced distributors.

A major implication of this study is the need to generate greater consensus within the scientific and medical community on recommendations to increase the impact of and compliance with the recommendations. Consensus recommendations may need to incorporate a broader range of stakeholders representing diverse perspectives. However, even if recommendations for DTC genetic testing were very clearly delineated today, implementation of such guidelines is still a problem. Until the evidence base for the validity and utility of genetic tests is well established and in the public domain, it will not be possible to ensure the accuracy of claims made about health-related DTC genetic testing products.

Achieving these goals will require greater investment in translation research for genetic discoveries in general [33] and better reporting mechanisms to include such information in the public domain. Evaluation and synthesis of the body of evidence supporting each genetic test will be critical given the lack of formal regulation and the inconsistent application of informal review for DTC genetic tests (e.g., by professional organizations, health insurers, expert opinion, consensus conference, or individual physicians) [34]. The complexity of the information means that such analyses need to be provided in a userfriendly format for both health professionals and consumers. Although neutral, respected groups already exist to commission systematic evidence-based reviews and assess the quality of evidence, such as the US Preventive
Services Task Force (USPSTF) or the Evaluation of Genomic Applications in Practice and Prevention (EGAPP) Working Group, these processes are non-regulatory, and given their limited resources, they must prioritize the review of the existing genetic tests. Development of clinical recommendations, whether evidence-based or expert/ consensus, should consider potential differences in the balance of benefits and harms (clinical utility) based on the mode of test delivery. For example, access to interventions following testing may differ depending on whether the test is conducted in a clinical setting or in a DTC setting.

In summary, the field of health-related DTC genetic testing is rapidly growing. Until now, there has been very little concrete data on compliance with recommended practices for DTC genetic testing. As this example illustrates, measuring and maintaining compliance with recommended practices is complicated by inconsistent recommendations from professional organizations. Establishing greater agreement in recommendations could lead to a greater responsibility to comply with those recommendations and improvement in the oversight of DTC genetic testing. Our findings highlight the urgent need for oversight, for greater consensus in recommendations for health-related DTC genetic tests, for greater responsibility on the part of DTC companies to comply with recommended practices, and for the development of improved resources for health care providers and consumers to assess existing tests.

\section{Acknowledgements}

This work was supported, in part, by fellowships (to K.G. and J.R.) jointly sponsored by the Centers for Disease Control and Prevention and the American Society of Human Genetics in Public Health Genomics Research and Practice. We have no conflicts of interest to report.

\section{References}

1 American College of Medicine Genetics Board of Directors. ACMG statement on direct-to-consumer genetic testing. Genet Med 2004;6:60.

2 National Society of Genetic Counselors Position Statement on Direct to Consumer Genetic Testing. Available at www.nsgc. org/about/position.cfm\#DTC. Accessed on March 10, 2008.
3 Hudson K, Javitt G, Buke W, Byers P, American Society of Human Genetics Social Issues Committee: ASHG statement on direct-to-consumer genetic testing in the United States. Am J Hum Genet 2007;81: 635-637.

4 Wolfberg AJ: Genes on the Web-direct-toconsumer marketing of genetic testing. N Engl J Med 2006;355:543-545.

5 Gray S, Olopade OI: Direct-to-consumer marketing of genetic tests for cancer: buyer beware. J Clin Oncol 2003;21:3191-3193.
6 McCabe LL, McCabe ER: Direct-to-consumer genetic testing: access and marketing. Genet Med 2004;6:58-59.

7 United States Government Accountability Office. Nutrigenetic testing: Tests purchased from four Web sites mislead consumers. Testimony to the US Senate Special Committee on Aging. GAO Document GAO-06-977T. GAO-06-977T. 2006. Washington, D. C., US Government Accountability Office. Available at http://www.gao.gov/new.items/ d06977t.pdf. 
8 Javitt GH: Pink or blue? The need for regulation is black and white. Fertil Steril 2006;86: 13-15.

9 Hull SC, Prasad K: Reading between the lines: direct-to-consumer advertising of genetic testing in the USA. Reprod Health Matters 2001;9:44-48.

10 Kessler DA, Levy DA: Direct-to-consumer advertising: is it too late to manage the risks? Ann Fam Med 2007;5:4-5.

11 Gilbody S, Wilson P, Watt I: Benefits and harms of direct to consumer advertising: a systematic review. Qual Saf Health Care 2005; $14: 246-250$

12 Stange KC: Time to ban direct-to-consumer prescription drug marketing. Ann Fam Med 2007;5:101-104.

13 Vastag B: US aims to tighten rules on directto-consumer drug ads. Nat Biotechnol 2007; 25:267.

14 Gollust SE, Wilfond BS, Hull SC: Direct-toconsumer sales of genetic services on the Internet. Genet Med 2003;5:332-337.

15 Chin KM, Wessler B, Chew P, Lau J: Technology Assessment: genetic tests for cancer. 290-02-0022. Agency for Healthcare Research and Quality, 2006. Available at http:// www.ahrq.gov/clinic/ta/gentests/gentests. pdf.

16 Secretary's Advisory Committee on Genetic Testing. Enhancing the oversight of genetic tests: recommendations of the SACGT. Bethesda, Md, National Institutes of Health, 2000. Available at http://www4.od.nih.gov/ oba/sacgt/reports/oversight_report.pdf.

17 Quality assurance and proficiency testing for molecular genetic testing: summary results of a survey of 18 OECD member countries. OECD, 2005. Available at http://www. oecd.org/dataoecd/25/12/34779945.pdf.

18 Andersson HC, Krousel-Wood MA, Jackson KE, Rice J, Lubin IM: Medical genetic test reporting for cystic fibrosis (deltaF508) and factor V Leiden in North American laboratories. Genet Med 2002;4:324-327.
19 Krousel-Wood M, Andersson HC, Rice J, Jackson KE, Rosner ER, Lubin I: Physicians' perceived usefulness of and satisfaction with test reports for cystic fibrosis (DeltaF508) and factor V Leiden. Genet Med 2003;5:166171.

20 Reich LM, Bower M, Key NS: Role of the geneticist in testing and counseling for inherited thrombophilia. Genet Med 2003;5:133143.

21 Guidance for industry: Consumer-directed broadcast advertisements. U.S. Department of Health and Human Services, Food and Drug Administration, Center for Drug Evaluation and Research (CDER), Center for Biologics Evaluation and Research (CBER), and Center for Veterinary Medicine (CVM), 1999. Available at http://www.fda.gov/cder/ Guidance/1804fnl.htm.

22 Guidance for industry: Brief summary: Disclosing risk information in consumer-directed print advertisements. U.S. Department of Health and Human Services, Food and Drug Administration, Center for Drug Evaluation and Research (CDER), and Center for Biologics Evaluation and Research (CBER), 2004. Available at http://www.fda. gov/cber/gdlns/consumad.htm.

23 Guidance for industry: Industry-supported scientific and educational activities. U.S. Department of Health and Human Services, Food and Drug Administration, 1997. Available at http://www.fda.gov/Cder/guidance/ isse.htm.

24 Dietary Supplements: An advertising guide for industry. Federal Trade Commission, 2001. Available at http://www.ftc.gov/bcp/ conline/pubs/buspubs/dietsupp.pdf.

25 Federal Trade Commission fact sheet on athome genetic tests: A healthy dose of skepticism may be the best prescription. Available at http://www.ftc.gov/bcp/edu/pubs/consumer/health/hea02.pdf. Accessed October 15, 2007.

26 Grody WW, Griffin JH, Taylor AK, Korf BR, Heit JA: American College of Medical Genetics consensus statement on factor $\mathrm{V}$ Leiden mutation testing. Genet Med 2001;3: 139-148.
27 Press RD, Bauer KA, Kujovich JL, Heit JA: Clinical utility of factor V Leiden (R506Q) testing for the diagnosis and management of thromboembolic disorders. Arch Pathol Lab Med 2002;126:1304-1318.

28 Koster T, Rosendaal FR, de Ronde H, Briet E, Vandenbroucke JP, Bertina RM: Venous thrombosis due to poor anticoagulant response to activated protein C: Leiden Thrombophilia Study. Lancet 1993;342:1503-1506.

29 Bertina RM, Koeleman BP, Koster T, Rosendaal FR, Dirven RJ, de Ronde H, van der Velden PA, Reitsma PH: Mutation in blood coagulation factor $\mathrm{V}$ associated with resistance to activated protein C. Nature 1994; 369:64-67.

30 Poort SR, Rosendaal FR, Reitsma PH, Bertina RM: A common genetic variation in the 3 '-untranslated region of the prothrombin gene is associated with elevated plasma prothrombin levels and an increase in venous thrombosis. Blood 1996;88:3698-3703.

31 Den Heijer M, Lewington S, Clarke R: Homocysteine, MTHFR and risk of venous thrombosis: a meta-analysis of published epidemiological studies. J Thromb Haemost 2005;3:292-299.

32 U.S. System of Oversight of Genetic Testing: A Response to the Charge of the Secretary of Health and Human Services, 2008. Available at http://www4.od.nih.gov/oba/SACGHS/ reports/SACGHS_oversight_report.pdf. Accessed on July 22, 2008.

33 Khoury MJ, Gwinn M, Yoon PW, Dowling N, Moore CA, Bradley L: The continuum of translation research in genomic medicine: how can we accelerate the appropriate integration of human genome discoveries into health care and disease prevention? Genet Med 2007;9:665-674.

34 Hudson KL, Murphy JA, Kaufman DJ, Javitt $\mathrm{GH}$, Katsanis SH, Scott J: Oversight of US genetic testing laboratories. Nat Biotechnol 2006;24:1083-1090. 